\title{
UNA APROXIMACIÓN DE LA PELÍCULA VIRUS A LA PANDEMIA DE LA COVID-19
}

\section{An Approximation of the Film Virus to the Pandemic of COVID-19}

\author{
Lynn Francis LAU-SANCHEZ; Karla Ximena BALCAZAR-ANICETO; Jorge PORRAS-GUILLERMO \\ Escuela de Medicina Humana, Facultad de Ciencias de la Salud, Universidad Privada Norbert Wiener, \\ Lima (Perú). \\ Correo electrónico: lilianglican20@gmail.com
}

Fecha de recepción: 18 de agosto de 2020

Fecha de aceptación: 10 de septiembre de 2020

Fecha de publicación: 29 de enero de 2021

\section{Resumen}

A lo largo del tiempo, el cine de ciencia ficción se ha convertido en un repertorio de información contrastable con la realidad. Es por ello, que se presenta el análisis de la película "Virus" de Sung-su Kim, donde el objetivo principal es presentar el filme al lector de manera que este pueda entender las pandemias representadas a través de las películas y compararla con la pandemia de la COVID19, de una manera objetiva, diferenciando una representación cinematográfica con la realidad. Como elaboración propia se presenta una tabla con las manifestaciones sistémicas de la COVID19 , realizadas con fuentes fidedignas; con esto se pretende la búsqueda de la sensibilización y educación del lector sobre una de las peores pandemias que actualmente estamos atravesando. Se concluye que la información vertida en los filmes relacionada a temas de salud debe ser interpretada de forma adecuada por los espectadores, separando lo real de lo ficticio. Por otro lado, la COVID-19 es una enfermedad que aún está en desarrollo y existe cada vez más evidencia de su compromiso sistémico.

Palabras clave: COVID-19; virus; sintomatología; pandemia.

\section{Abstract}

Through the years, science fiction cinema has become a repertoire of information that can be contrasted with reality. That is why we present the analysis of the film 'Virus' by Sung-su Kim, where 
UNA APROXIMACIÓN DE LA PELÍCULA VIRUS A LA PANDEMIA DE LA COVID-19

LYNN FRANCIS LAU-SANCHEZ; KARLA XIMENA BALCAZAR-ANICETO; JORGE PORRAS-GUILLERMO

the main objective is to present the film to the reader so that he can understand the pandemics represented through the films and compare it with the pandemic of the COVID-19 in an objective way, differentiating a cinematographic representation with reality. As an own elaboration, we present a table with the systemic manifestations of the COVID-19, made with reliable sources; with this we intend to seek the awareness and education of the reader about one of the worst pandemics we are currently going through. The conclusion is that the information given in the films related to health issues must be interpreted appropriately by the viewers, separating the real from the fictitious. On the other hand, COVID-19 is a disease that is still developing and there is increasing evidence of its systemic commitment.

Keywords: COVID-19; virus; symptomatology; pandemic.

\section{FICHA TÉCNICA}

Título: Virus.

Título original: Gamgi.

País: Corea del Sur.

Año: 2013.

Director: Sung-su Kim.

Música: Tae-seong Kim.

Fotografía: Mo-gae Lee.

Montaje: Na-young Nam.

Guion: Young-jong Lee, Sung-soo Kim, Jae-ho Jung Intérpretes: Hyuk Jang (Kang Ji-koo), SooAe (Kim In-hae), Hee-joon Lee (Byung-ki), Sang-Yeob Lee (Byeong-woo), Min-ah Park (Kim Mi-reu)...

Color: color.

Duración: 122 minutos.

Género: acción, drama, ciencia ficción.

Productoras: iLoveCinema, iFilm Co.

Sinopsis: La peor epidemia jamás vista está arrasando Bundang, un suburbio de Seúl, capital de Corea del Sur. Después de introducir a una serie de inmigrantes ilegales en el país, Byungwoo muere a causa de un virus desconocido. Poco después, los mismos síntomas aparecen en otros residentes de la zona. El pueblo se siente indefenso ante un virus que se transmite por el aire y con un número de afectados que crece rápidamente, desatando el caos. Con una de las medidas más extremas para poder prevenir la expansión, la ciudad en la que viven más de 19 millones de habitantes se prepara para cerrar por completo sus fronteras por órdenes del gobierno. Mientras tanto, el especialista vírico In-hye y el rescatista Ji-goo se adentran en la ciudad para obtener una muestra de sangre del "paciente cero", una parte crucial de la investigación para tratar de fabricar una vacuna.

\section{Enlaces:}

https://www.imdb.com/title/tt2351310 /?ref_=ttpl_pl_tt https://www.filmaffinity.com/es/film695 844.html

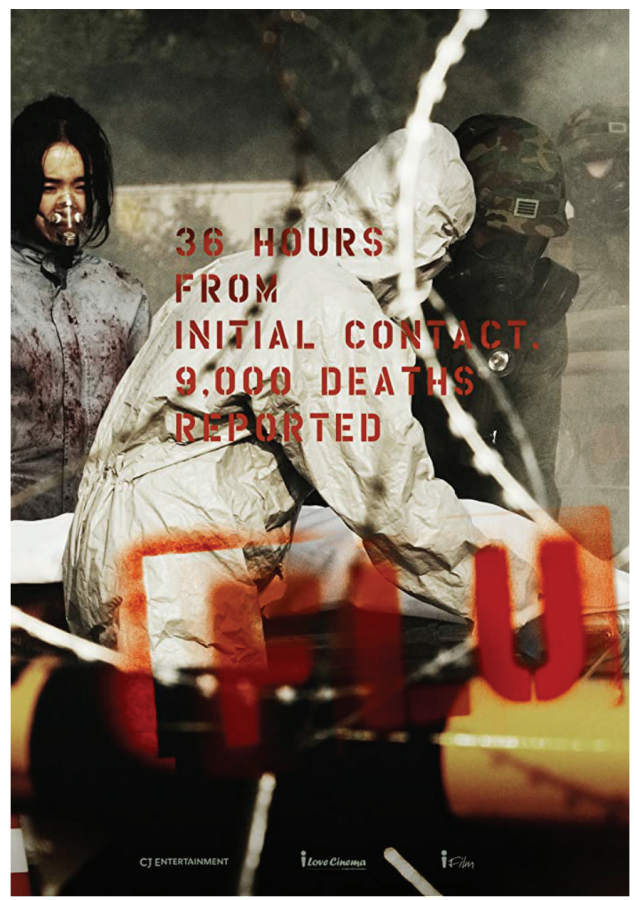


UNA APROXIMACIÓN DE LA PELÍCULA VIRUS A LA PANDEMIA DE LA COVID-19

LYNN FRANCIS LAU-SANCHEZ; KARLA XIMENA BALCAZAR-ANICETO; JORGE PORRAS-GUILLERMO

INTRODUCCIÓN

El mundo está atravesando por una de las peores pandemias de la historia debido a la COVID-19, una enfermedad de inicio reciente que fue capaz de colapsar muchos sistemas de salud $^{1,2}$. Hasta el momento quedan muchas dudas e interrogantes sobre todo lo que engloba esta enfermedad, mientras tanto el número de contagios y muertes se encuentran en ascenso. Esta situación ha despertado mucho interés en las personas por conocer más acerca de la pandemia y recurren a la investigación de muchas fuentes que varían en cuanto a la veracidad de la información que transmiten. Dentro de estas fuentes, el cine es uno de los principales representantes.

A lo largo del tiempo, el cine ha influenciado notablemente en las personas ${ }^{3}$, llegando a tener miles de producciones basadas en hechos reales y de otros miles en ficción. Si bien la finalidad de las películas es mostrar producciones audiovisuales, estas terminan teniendo gran impacto en la sociedad sobrepasando incluso la realidad. En este contexto, tratándose de una película que involucra temas de la salud y además, de estar acorde a la situación actual, existe la necesidad de diferenciar lo ficticio de lo real, ya que podría generar desinformación o tergiversar los conceptos en los espectadores. Este es el caso de la película "Virus", donde se ha sacrificado el lado documental y el aspecto médico para dar vida a la ficción.

El presente artículo está estructurado de la siguiente manera: Primero se muestra un resumen de la película "Virus" (2013). Luego, se da a conocer una crítica sobre la epidemia que se muestra en el filme. Además, se presenta información resaltante ya conocida hasta la actualidad sobre la COVID-19. Posteriormente, se muestra una revisión de evidencia científica recientemente publicada donde se sintetizan las manifestaciones clínicas relacionadas a la COVID-19 organizada por sistemas y finalmente se muestran las conclusiones para el interés del lector.
TRAMA

Virus es una película basada en una epidemia que ocurrió en Corea del Sur, en la ciudad de Bundang-gu, donde hay una proliferación de un virus no identificado. La historia inicia con el relato de un par de hermanos coreanos contrabandistas en Seúl, quienes al abrir un contenedor durante la noche descubren inmigrantes ilegales fallecidos y cubiertos de sangre (Foto 1). En el lugar solo quedaba un sobreviviente llamado Monssai. Los hermanos empezaron a registrar la escena con su teléfono móvil, el sobreviviente se exalta e intenta huir. Uno de los hermanos, en el intento de retener al sobreviviente, se coloca mal la mascarilla y se expone en medio de los muertos. Ante la exposición, este personaje se contagia e inicia la propagación del virus.

Al día siguiente, el hermano contagiado manifiesta algunos signos y síntomas, y se dirige a una farmacia para tratar sus malestares; en esta escena se observa el mecanismo de transmisión del virus entre personas por medio de las gotitas de flugge (Foto 2). Después de un tiempo, el infectado presenta complicaciones de sus manifestaciones clínicas, por este motivo acude a emergencias.

El personal de emergencias aísla al infectado y lo coloca bajo cuarentena por el cuadro clínico que presentaba: tos seca, garganta inflamada, lesiones en la piel, hemoptisis, fiebre mayor a $40^{\circ} \mathrm{C}$, leucopenia, presión sanguínea inestable, síndrome de disfunción múltiple de órganos, debilidad y esclerótica inflamada (Foto 3 ).

Mientras tanto, en la ciudad se evidencia el contagio, transmisión y propagación del virus. Por tal motivo, los hospitales colapsan y se evidencia una mala atención y manejo de personas. Con la ayuda de los médicos del centro de control de enfermedades y prevención logran localizar el contenedor y queman toda la zona donde se inició la epidemia. Al encontrar roedores dentro del contenedor, los especialistas piensan que posiblemente podrían estar infectadas. Luego, 


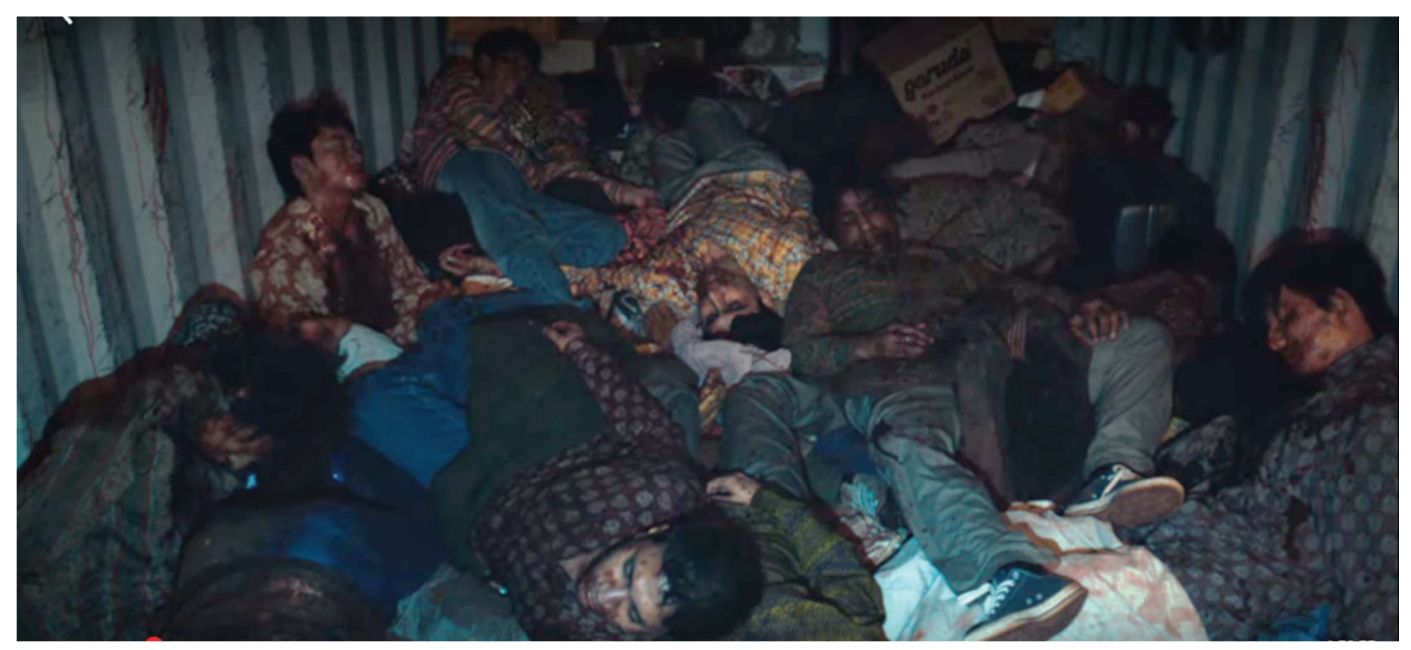

Foto 1. Inicio de la propagación de un virus importado.

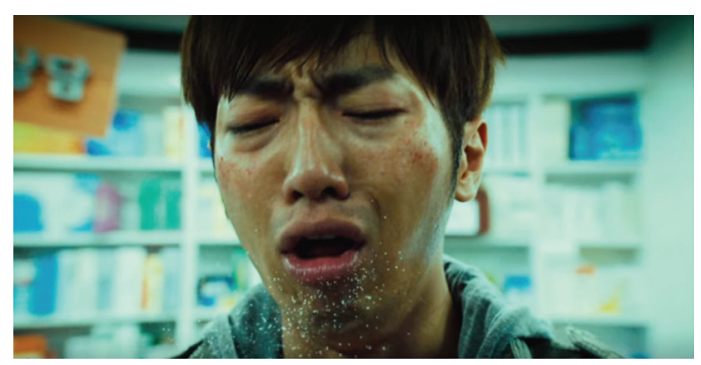

Foto 2. Mecanismo de transmisión de la gripe aviar a través de gotitas de flugge.

se determinó que se trataba de una enfermedad agresiva y el microorganismo causante era el virus H5N1, el cual podría causar la muerte en 3 días, es por ello por lo que se impone a la población permanecer en cuarentena. Las personas entran en pánico por el repentino brote. La policía antidisturbios intenta hacer control inmediato mientras rastrean y tratan de contener a la gente que muestra el contagio, incurren en negligencias, los ciudadanos entran en pánico y caos, llegando incluso a ser encerrados dentro de un supermercado sin explicación.

Por la noche toda la población es trasladada a un campamento. Al momento de realizar

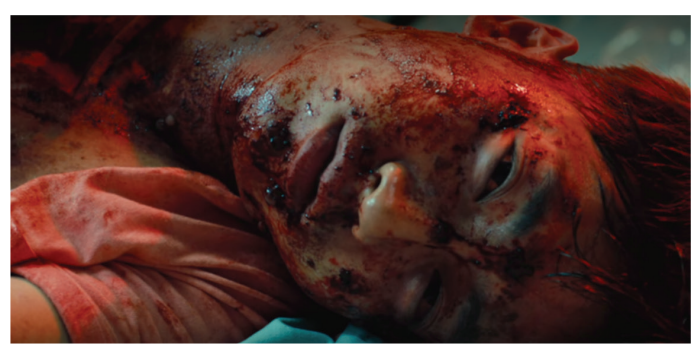

Foto 3. Manifestaciones clínicas de la gripe aviar

el examen físico y la toma de muestra para la prueba molecular (Foto 4), Kim in-hae se da cuenta que su hija Mi-reu estaba enferma y decide ocultar su enfermedad. A medida que pasa el tiempo Mi-Reu comienza a presentar más manifestaciones clínicas, el rescatista Kang Ji-Koo se da cuenta que la niña tenía erupciones en la piel, la doctora Kim in-hae le manifiesta que no existe tratamiento médico y por ese motivo no quiere entregar a su hija. Luego de 42 horas de aislamiento, el equipo médico encuentra a Monssai en la zona de infectados y lo trasladan al laboratorio para hacerle pruebas y analizar si es posible desarrollar una vacuna. Kim In-hae ve 


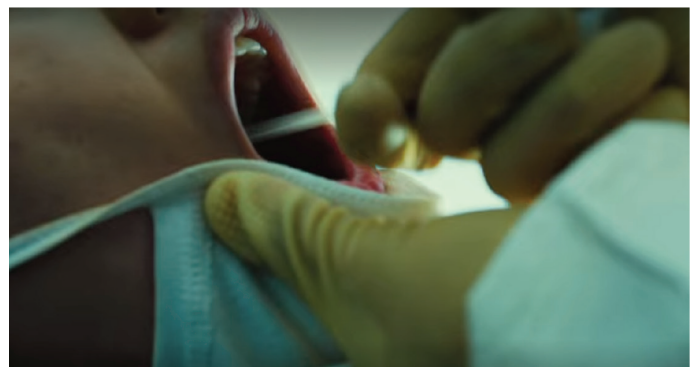

Foto 4. Obtención de muestra biológica para el diagnóstico.

una oportunidad para salvar a su hija y decide llevarla oculta al laboratorio.

La doctora Kim In-hae tiene el juicio nublado por el miedo de perder a su hija debido al rápido avance de las lesiones, no considera los protocolos ni su ética médica y ante la negativa, decide tomar acción por su cuenta. Monssai es evaluado en el laboratorio y por confianza en el equipo, dejan a Kim In-hae sola para monitorearlo. La doctora ve la oportunidad y actúa rápidamente, entonces decide procesar una muestra para inyectarle los anticuerpos a su hija (Foto 5). En ese preciso momento, los soldados ingresan e intervienen el lugar, lanzándole un dardo tranquilizador a Kim In-Hae y llevándose a la pequeña Mi-reu a la zona de infectados. Kang Ji-Koo localiza a la niña mientras Kim in-hae se ve forzada a huir, pues al ser un personal médico las personas la querían agredir. La doctora sube a la movilidad en la que transportaban a Monssai, pero una de las personas era uno de los hermanos contrabandistas, al ver al joven, decide vengar a su hermano por haberlo contagiado, y Monssai es acuchillado. La única persona que contenía los anticuerpos fallece.

La doctora Kim In-hae afirma al presidente que su hija asimiló los anticuerpos y hubo mejoría en sus síntomas, pero el ministro da la orden de alzar fuego a las personas que crucen la franja naranja que significaba el límite entre

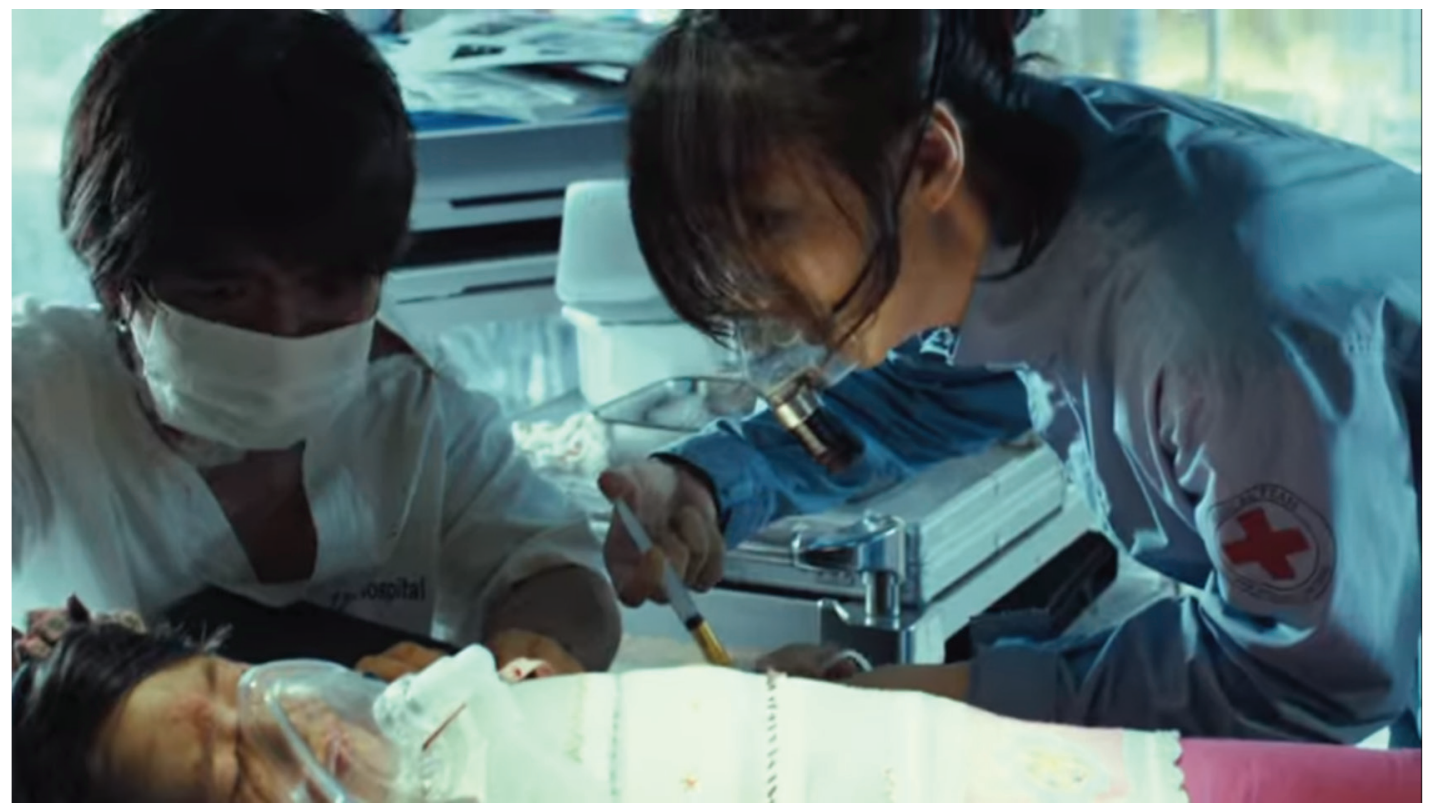

Foto 5. Aplicación de plasma rico en anticuerpos contra el virus. 
la ciudad y el acceso a la capital. Al ver que la niña había superado la infección, por sus características clínicas visibles, los doctores solicitan detener el ataque. Transportan a Mi-reu y Kang Ji-koo para realizar las pruebas de anticuerpos y así puedan salvar a miles de personas. Finalmente, la prensa comunica a la población que Mi-reu es la portadora de los anticuerpos, y que gracias a esto se desarrollará una vacuna.

\section{CRÍTICA DE LA PELÍCULA}

La pandemia de la COVID-19 que estamos atravesando, es una situación que podría generar pánico y frustración para muchas personas a nivel mundial. La película "Virus" plantea un ambiente similar en el que nos encontramos, mostrando un posible apocalipsis del 2020. La realidad y la ficción son escenarios completamente distintos, pero, actualmente podrían causar en el espectador la sensación de vivir una película en carne propia. Si bien la finalidad del filme no es instruir a los espectadores, esta podría considerar escenas más cercanas a la realidad.

Existen ciertas similitudes mostradas durante la película, un ejemplo simple sería la escena en la cual se informa a la población de la situación sanitaria y todos se desesperan generando desorden en las calles, caso muy parecido a nuestro entorno. Si observamos la transmisión mediante las gotitas de flugge en la escena de la farmacia es la misma a la de la COVID-19, esparcidas por todo el ambiente e inhaladas por los presentes causando así la sintomatología típica ${ }^{4}$.

Se debe considerar que, en la película, la transmisión del virus es sumamente rápida; sin embargo, en la COVID-19 existe un periodo de incubación de 5 días $^{5}$. La sintomatología es muy similar porque en ambos escenarios el paciente presenta tos seca, siendo esta un síntoma principal, después se le agrega la hemoptisis, fiebre y lesiones en la piel.
Otro punto importante es la utilización del material de bioseguridad y las medidas adecuadas que debieron mostrar en la película como enseñanza a sus espectadores para así evitar la propagación desmedida del virus. Se visualiza una escena donde reclutan a las personas para las toma de muestras pero se observa que sólo algunos poseen una mascarilla y otras no, a pesar de que todos ellos están bajo vigilancia con personal capacitado.

No debemos dejar de lado uno de los puntos cruciales durante el desarrollo de la película, el comportamiento de las entidades políticas frente a una situación de crisis. Vemos que hay dos posiciones muy marcadas y opuestas: Por un lado, la actitud y decisión de un presidente que, frente al riesgo de desaprobación o consecuencias políticas con potencias mundiales, antepone el bienestar de un grupo minoritario pero humano y por otro, a un grupo de políticos que, frente al riesgo de una amenaza, toma decisiones radicales ante la hipótesis de "un sacrificio por un bien mayor". Sin duda, estos comportamientos pueden llegar a ser muy comparables con las situaciones políticas actuales.

"Virus" ha causado gran impacto en los espectadores y muchos lo han llegado a relacionar a la pandemia de la COVID-19, estas personas ven reflejado el contexto actual en toda la trama de la película, la cual está plagada de emoción y suspenso. En gran parte de la película se pone especial énfasis en la cura, generando esperanza al espectador, quien se identifica con las circunstancias, pecando de optimismo o desinformación debido a que en la película no se realizó ningún estudio científico para dar supuestamente una solución a la enfermedad. Por ejemplo, mediante el uso de una vacuna efectiva. Sin embargo, la recuperación de Mi-reu fue extremadamente eficaz luego de la terapia de inmunización pasiva, sin ensayos previos, y esto puede mostrar al espectador una idea errónea de la medicina. 
"Virus" por un lado muestra un panorama que carece de contenido real en el aspecto médico y político, ocasionando un temor innecesario al espectador, pero por otro lado añade cierta ilusión contraria a la ciencia, lo cual es producto de una situación de vulnerabilidad y estrés propio del contexto actual.

\section{COVID-19}

La pandemia actual está asociada a la infección por el virus SARS-CoV-2, causante de la COVID-19, una situación que puso de manifiesto la vulnerabilidad de la población mundial frente a nuevos microorganismos. A fines de diciembre del 2019, múltiples casos de neumonía de etiología desconocida fueron reportados en algunos hospitales de Wuhan, provincia de Hubei, China. Los casos tenían una historia de exposición a mercado de productos marinos y animales exóticos de dicha localidad. Luego se confirmó que la enfermedad respiratoria era causada por un nuevo coronavirus ${ }^{6}$.

Los coronavirus (CoV), una gran familia de ARN virus monocatenarios, pueden infectar animales, humanos y son capaces de causar enfermedades respiratorias, gastrointestinales, hepáticas y neurológicas ${ }^{7}$. Los coronavirus pertenecen a la familia Coronaviridae y al orden Nidovirales ${ }^{8}$. Son viriones que poseen envoltura y, además, tienen el genoma más largo de ARN de cadena positiva, miden entre 80 y $160 \mathrm{~nm}$ de diámetro y poseen glucoproteínas en su superficie en forma de bastón $n^{9}$. Los CoV se dividen en cuatro géneros: alfa-coronavirus, beta-coronavirus, gamma-coronavirus y delta-coronavirus ${ }^{10}$. El SARS-CoV-2 es del género beta-coronavirus. La transmisión entre humanos es por gotitas de flugge, esta es la ruta principal de transmisión además del contagio por contacto con superficies ${ }^{4}$. Se le denomina SARS porque causa el síndrome respiratorio agudo grave ${ }^{5}$.
El riesgo de enfermarse gravemente a causa del COVID-19 aumenta con la edad, por lo que los adultos mayores tienen mayor riesgo a presentar complicaciones. Asimismo, personas de cualquier edad con factores de riesgo están predispuestas a enfermarse de forma grave, las patologías asociadas son: Enfermedad renal crónica (ERC), Enfermedad pulmonar obstructiva crónica (EPOC), personas inmunodeprimidas por trasplante de órganos sólidos, obesidad (IMC $\geq$ 30), enfermedad de células falciformes, diabetes mellitus tipo 2, afecciones cardiacas graves, insuficiencia cardiaca y enfermedad de las arterias coronarias o miocardiopatías ${ }^{11}$.

\section{MANIFESTACIONES CLínICAS DE LA COVID-19}

Esta enfermedad no solo se presenta una sintomatología típica de un proceso respiratorio y por la evidencia científica se demuestra que la afección se da también a nivel de diferentes órganos y sistemas. Se realizó una revisión de las manifestaciones clínicas, las cuales están organizadas por sistemas (Tabla 1).

El compromiso más importante se da a nivel del sistema respiratorio. Existe un estudio donde se manifiesta que los signos y síntomas más frecuentes son: tos, disnea y fiebre. Este estudio fue de cohorte prospectivo en 20,133 pacientes de 208 hospitales de cuidados agudos en Inglaterra, Escocia y Gales, con un seguimiento desde el 6 de febrero hasta el 19 de abril del 2020. Adicionalmente, se observaron otros tres grupos: uno que abarca síntomas músculo-esqueléticos (mialgia, dolor en las articulaciones, dolor de cabeza y fatiga), síntomas entéricos (dolor abdominal, vómitos y diarrea) y menos común, un grupo mucocutáneo ${ }^{12}$.

Sin embargo, aún existen vacíos en cuanto a las manifestaciones clínicas en algunos sistemas del cuerpo humano causado por la COVID-19, como en el caso del sistema endocrino ${ }^{13}$, donde solo existe información hipotética hasta la actualidad. 
UNA APROXIMACIÓN DE LA PELÍCULA VIRUS A LA PANDEMIA DE LA COVID-19

LYNN FRANCIS LAU-SANCHEZ; KARLA XIMENA BALCAZAR-ANICETO; JORGE PORRAS-GUILLERMO

Tabla 1: Manifestaciones sistémicas de la COVID-19

\begin{tabular}{|c|c|c|}
\hline Sistemas & Manifestaciones Clínicas & Referencias \\
\hline Sistema Respiratorio & Tos seca, fiebre, dificultad para respirar, esputo. & -Docherty et al., $2020^{12}$. \\
\hline $\begin{array}{l}\text { Sistema } \\
\text { Musculoesquelético }\end{array}$ & $\begin{array}{l}\text { Mialgia, dolor en las articulaciones, dolor de cabeza y } \\
\text { fatiga. }\end{array}$ & -Docherty et al., $2020^{12}$. \\
\hline Sistema Nervioso & $\begin{array}{l}\text { Dolor de cabeza, anosmia, ageusia, deterioro de } \\
\text { la conciencia, convulsión, encefalitis, confusión, } \\
\text { encefalopatía y signos del tracto cortico espinal en el } \\
\text { examen, así como realce leptomeníngeo y anormalidades } \\
\text { de perfusión en la resonancia magnética (MRI), síndrome } \\
\text { de Guillain Barré, hiposmia o anosmia, disgeusia o } \\
\text { ageusia. }\end{array}$ & -Zubair et al., $2020^{14}$. \\
\hline Sistema Cardiovascular & $\begin{array}{l}\text { Miocarditis fulminante, arritmias, hipoxia, hipertensión, } \\
\text { lesión miocárdica, insuficiencia cardíaca, cardiopatía } \\
\text { isquemia, anomalías de la coagulación intravascular } \\
\text { diseminada, bradicardia, miocarditis, shock cardiogénico. }\end{array}$ & $\begin{array}{l}\text {-Guzik et al., } 2020^{15} \text {. } \\
\text {-Dhakal et al., } 2020^{16} \text {. }\end{array}$ \\
\hline Sistema Digestivo & $\begin{array}{l}\text { Nauseas, vómitos, diarreas, dolor abdominal, falta de } \\
\text { apetito. }\end{array}$ & $\begin{array}{l}\text {-Parra et al., } 2020^{17} \\
\text {-Yang et al.,2020 }\end{array}$ \\
\hline Sistema Urinario & $\begin{array}{l}\text { Proteinuria, hematuria, creatinina sérica elevada, } \\
\text { nitrógeno ureico en sangre elevado, filtración glomerular } \\
\text { estimada por debajo de } 60 \mathrm{ml} / \mathrm{min} \text {, lesión renal aguda, } \\
\text { glomerulopatía colapsante. }\end{array}$ & $\begin{array}{l}\text {-Cheng et al., } 2020^{19} \text {. } \\
\text {-Kissling et al., } 2020^{20} \text {. }\end{array}$ \\
\hline Sistema Óptico & Conjuntivitis ocular & -Aiello et al., $2019^{21}$. \\
\hline Sistema Dermatológico & $\begin{array}{l}\text { Erupciones edematosas, picazón o dolor, pápulas, } \\
\text { máculas eritematoso-violáceas, ampollas, inflamación } \\
\text { digital, erupciones acrales, sabañones en los dedos, } \\
\text { petequias, urticarias, exantema intertriginoso, eritema } \\
\text { multiforme, erupción maculopapular, alopecia } \\
\text { androgénica. }\end{array}$ & -Wollina et al., $2020^{22}$ \\
\hline Sistema Hematológico & $\begin{array}{l}\text { Trombosis, coagulopatía inducida por sepsis, elevación } \\
\text { prominente de dímero } \mathrm{D} \text { y productos de degradación de } \\
\text { fibrina y fibrinógeno. }\end{array}$ & -Connors et al., $2020^{23}$. \\
\hline
\end{tabular}

Elaboración propia.

\section{CONCLUSIONES}

Las producciones cinematográficas pueden ser una herramienta muy útil para la sensibilización y educación de los espectadores en cuanto a temas médicos se refieran. Sin embargo, el espectador debe ser capaz de discernir entre lo real y lo ficticio, para evitar confusiones y falsas creencias.

Se debe tener en cuenta que la sintomatología de la COVID-19 no es típica de una infección viral y no es esencialmente de tipo respiratorio, sino es más de compromiso sistémico. Además, existe mucho interés en la población por conocer más a fondo esta enfermedad, se recomienda la utilización de evidencia científica fidedigna, fiable y reciente para conocer más sobre ella, y de esta forma evitar la divulgación de información que no se ajusta a la realidad y que podría perjudicar a muchas personas. La COVID-19 es una enfermedad 


\author{
UNA APROXIMACIÓN DE LA PELÍCULA VIRUS A LA PANDEMIA DE LA COVID-19 \\ LYNN FRANCIS LAU-SANCHEZ; KARLA XIMENA BALCAZAR-ANICETO; JORGE PORRAS-GUILLERMO
}

en desarrollo, por eso hasta el momento existe mucha incertidumbre en torno a sus manifestaciones clínicas, ya que se va agregando nuevos signos y síntomas con el transcurrir del tiempo.

\section{AGRADECIMIENTOS}

Al Dr. Hans Contreras-Pulache, por la dedicación y apoyo brindado a este trabajo, por el respeto a nuestras sugerencias e ideas, por la dirección y contribución con la investigación científica en nuestra universidad.

A nuestro compañero Javier Sevillano-Jiménez, por su disposición para compartir sus conocimientos y por la motivación para la elaboración del trabajo.

A nuestro compañero Jacob Sánchez-Montoya, por su tiempo y disponibilidad con la traducción.

A nuestros familiares por su gran apoyo moral y humano, por ser nuestro motor y motivo para seguir adelante.

\section{REFERENCIAS}

1. Legido-Quigley H, Mateos-García J, Campos V, Gea-Sánchez M, Muntaner C, McKee M. The resilience of the Spanish health system against the COVID-19 pandemic. Lancet Public Health. 2020;5(5):251-2.

2. Armocida B, Formenti B, Ussai S, Palestra F, Missoni E. Italian health system and the COVID-19 challenge. Lancet Public Health. 2020;5(5):253.

3. Zorroza M. Ficción, experiencia y realidad ¿Qué tiene que ver el cine con la vida? Revista de Comunicación. 2007;(6):70-80.

4. Ying-Hui J, Cai L, Zhen-Shun C, Cheng H, Deng T, $\mathrm{Yi}-\mathrm{Pin} \mathrm{F}$, et al. A rapid advice guideline for the diagnosis and treatment of 2019 novel coronavirus (2019-nCoV) infected pneumonia. Mil Med Res. 2020;7(4):1-23.

5. Lauer S, Grantz K, Bi Q, Jones F, Zheng Q, Meredith $\mathrm{H}$, et al. The Incubation Period of Coronavirus Disease 2019 (COVID-19) From Publicly Reported Confirmed Cases: Estimation and Application. Ann Intern Med. 2020;172(9):577-82.
6. Zhu N, Zhang D, Wang W, Li X, Yang B, Song J, et al. A novel coronavirus from patients with pneumonia in China, 2019. N Engl J Med. 2019;382:727-33.

7. Weiss S, Leibowitz J. Coronavirus pathogenesis. Adv Virus Res. 2011;81:85-164.

8. Richman D, Whitley R, Hayden F. Clinical virology. 4th ed. Washington: ASM Press; 2016.

9. Murray P, Rosenthal K, Pfaller M. Microbiología médica. 8th ed. Barcelona: Elsevier; 2017.

10. Yang D, Leibowitz J. The structure and functions of coronavirus genomic 3' and 5'ends. Virus Res. 2015;206:120-33.

11. CDC. [Internet]. Enfermedad del coronavirus 2019 (COVID-19). Centers for Disease Control and Prevention. [Consultado el 28 de julio de 2020].

12. Docherty A, Harrison E, Green C, Hardwick H, Pius R, Norman L, et al. Features of 20133 UK patients in hospital with covid-19 using the ISARIC WHO Clinical Characterisation Protocol: prospective observational cohort study. BMJ. 2020;369:m1985.

13. Pal R, Banerjee M. COVID-19 and the endocrine system: exploring the unexplored. J Endocrinol Invest. 2020;43(7):1027-31.

14. Zubair A, McAlpine L, Gardin T, Farhadian S, Kuruvilla D, Spudich S. Neuropathogenesis and Neurologic Manifestations of the Coronaviruses in the Age of Coronavirus Disease 2019. JAMA Neurol. 2020;77(8):1018-27.

15. Guzik T, Mohiddin S, Dimarco A, Patel V, Savvatis $\mathrm{K}$, Marelli-Berg F, et al. COVID-19 and the cardiovascular system: implications for risk assessment, diagnosis, and treatment options. Cardiovasc. Res. 2020;116(10):1666-87.

16. Dhakal B, Sweitzer N, Indik J, Acharya D, William P. SARS-CoV-2 Infection and Cardiovascular Disease: COVID-19 Heart. Heart Lung Circ. 2020;29(7): 973-87.

17. Parra V, Flórez C, Romero-Sánchez M, García del Risco F. Síntomas gastrointestinales en la enfermedad por COVID-19 y sus implicaciones en enfermedad inflamatoria intestinal. Rev Colomb Gastroenterol. 2020;35(Supl.1):45-55.

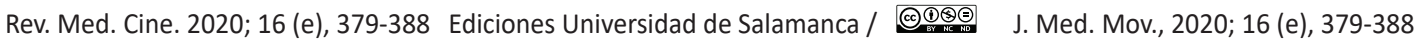


18. Yang L, Tu L. Implications of gastrointestinal manifestations of COVID-19. Lancet Gastroenterol Hepatol. 2020;5(7):629-30.

19. Cheng Y, Luo R, Wang K, Zhang M, Wang Z, Dong $\mathrm{L}$, et al. Kidney disease is associated with in-hospital death of patients with COVID-19. Kidney Int. 2020;95(5):829-38.

20. Kissling S, Rotman S, Gerber C, Halfon M, Lamoth F, Comte D, et al. Collapsing glomerulopathy in a COVID19 patient. Kidney Int. 2020;98(1):228-31.
21. Aiello F, Gallo Afflitto G, Mancino R, J-Peng L, Cesareo M, Giannini C, et al. Coronavirus disease 2019 (SARS-CoV-2) and colonization of ocular tissues and secretions: a systematic review. Eye. 2020;34:1206-11.

22. Wollina U, Karadağ A, Rowland-Payne C, Chiriac A, Lotti T. Cutaneous signs in COVID-19 patients: A review. Dermatol Ther. 2020;e13549.

23. Connors J, Levy J. COVID-19 and its implications for thrombosis and anticoagulation. Blood. 2020;135(23):2033-40.

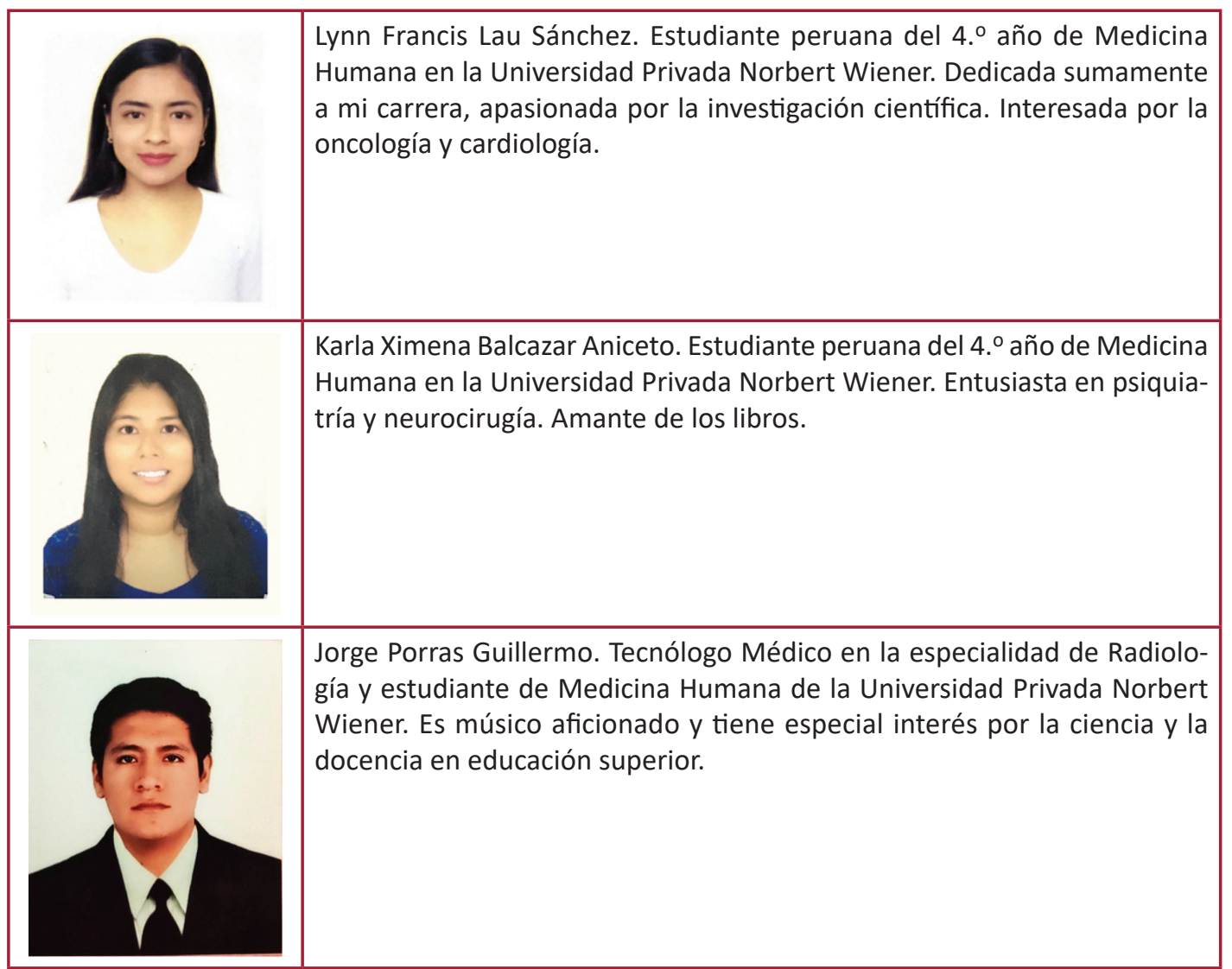

